Demanda contínua 



\title{
Educação em classes hospitalares: transformando ações e concepções à luz da teoria da complexidade
}

\section{Education in hospital class: transforming actions and conceptions to the light of the theory of complexity}

\author{
Sinara Pollom Zardo* \\ Soraia Napoleão Freitas**
}

\begin{abstract}
RESUMO
O presente artigo objetiva discutir a educação em classes hospitalares em vista da crescente expansão desses ambientes educacionais. Nesse sentido, pretende-se aliar a organização institucional do hospital a pressupostos teóricos que permitam pensar uma nova concepção educacional que considere a complexidade do sujeito em hospitalização, partindo da valorização da sua condição humana e existencial e da superação de processos disjuntivos que caracterizam o tratamento da criança hospitalizada. Para tal, serão utilizadas porções teóricas de Santos (2002a, 2002b, 2002c), Morin (2002, 2003), Ceccim (1997), Ortiz (2002, 2003), Fonseca (2003) e demais autores que nos auxiliem a discutir hipóteses inerentes à prática educativa em hospitais nos espaços das classes hospitalares, fornecendo subsídios para enfrentar a transição paradigmática e para conseguir identificar as vibrações ascendentes do paradigma emergente. Com isso, apontamos a necessidade de desenvolver uma atitude estratégica sustentada na crítica do paradigma hegemônico e de invenções credíveis de novas formas de conhecimento e organização em ambientes educacionais hospitalares que primem pelo atendimento integral à criança hospitalizada. Dessa forma,
\end{abstract}

* Mestranda em Educação do Programa de Pós-Graduação em Educação UFSM, Linha de Pesquisa em Educação Especial, Bolsista Proesp/Capes/. E-mail: sinara@mail.ufsm.br

** Orientadora da pesquisa, Professora Doutora do Departamento de Educação Especial e do Programa de Pós-Graduação em Educação/UFSM, Líder do Grupo de Pesquisa - CNPq Educação Especial: Interação e Inclusão Social. 
ZARDO, S. P.; FREITAS, S. N. Educação em classes hospitalares: transformando ações e concepções à luz da teoria da complexidade

recorremos à teoria da complexidade para melhor compreender a condição humana e, em conseqüência, impedir a estruturação de princípios fragmentadores no processo de desenvolvimento organizacional das instituições de saúde e educação.

Palavras-chave: educação; classe hospitalar; complexidade humana.

\begin{abstract}
The present article discusses the education in hospital class because of the expansion of those educational atmospheres. In that sense, it intends to ally the institutional organization of the hospital to theoretical presuppositions that allow to think a new educational conception that considers the subject's complexity in hospitalization, starting from the appreciation of their human and existential condition and of the overcome of disjunctive processes that characterized the hospitalized child's treatment. For such, theoretical portions of Santos will be used (2002a, 2002b, 2002c), as well as Morin (2002, 2003), Ceccim (1997), Ortiz (2002, 2003), Fonseca (2003) and other authors that help us discuss inherent hypotheses to the educational practice in hospitals, offering subsidies for us to face the paradigmatic transition and identify the ascending vibrations of the emergent paradigm. Thus, we pointed the need to develop a strategic attitude sustained in the critic of the hegemonic paradigm and of certified inventions in new knowledge and organization forms in educational hospital environments that excel for the integral attendance to the hospitalized child. In that way, we used the theory of complexity for a better understanding of the human condition and thus to avoid the structuring of fragmenting principles in the process of organizational development of health and education institutions.

Key-words: education; hospital class; human complexity.
\end{abstract}

O presente artigo tem como base as experiências pedagógicas vivenciadas em ambiente hospitalar pela realização de projetos de iniciação científica que primavam pelo atendimento educacional à criança hospitalizada. Com essas práticas, foi possível o ingresso no espaço hospitalar atuando como docente, desvelando horizontes desconhecidos em relação a esses ambientes de ensino.

Essas experiências demonstraram que a promoção de ambientes educacionais e lúdico-terapêuticos nos hospitais contribui de forma ímpar para o enfrentamento das enfermidades por parte das crianças hospitalizadas, amenizando possíveis traumas. Essas iniciativas auxiliam, da mesma forma, a tornar o hospital um ambiente humanizador e contribuem para que o período de hospitalização se constitua num evento que pode ser compreendido pelo paciente, sendo con- 
siderado uma ocasião em que a subjetividade e os conhecimentos continuam a ser construídos, simultaneamente à recuperação.

Nesse sentido, o presente texto busca retratar algumas inquietações referentes à prática educacional em ambientes hospitalares, considerando a necessidade de promover um atendimento pedagógico que considere a complexidade inerente à condição humana da criança em tratamento, analisando os pilares que sustentam o processo de desenvolvimento organizacional desses espaços de ensino.

Outro aspecto a ser considerado é a provisoriedade do acompanhamento educacional realizado, uma vez que as crianças hospitalizadas são alunos temporários da educação especial, e a heterogeneidade, no que tange à faixa etária e os lugares de onde os paciente-alunos são provenientes.

Embora a temática "classe hospitalar" ainda seja considerada muitas vezes desconhecida e inexplorada pelos educadores e pesquisadores das Ciências Humanas, esta proposta baseia-se em pesquisas realizadas por Fonseca (2003), Ceccim (1997) e Ortiz (2002), que, em linhas gerais, buscam contemplar a educação em ambientes hospitalares, justificando a necessidade desses espaços educativos para o desenvolvimento integral da criança em tratamento.

Configurando alguns resultados de pesquisas, pode-se citar Fonseca (2003), que desenvolveu um estudo que demonstrou a existência de oitenta e cinco classes hospitalares distribuídas em 14 estados brasileiros e no Distrito Federal. Quanto à realidade desses ambientes de ensino, a pesquisadora relata que poucas informações retornaram, sendo, portanto, impossível a verificação de detalhes que evidenciassem os pressupostos da prática pedagógica.

Por sua vez, Ortiz (2002) empenhou-se na tarefa de investigar o fazer didático construído na prática educacional de seis classes hospitalares brasileiras, definindo como critério de escolha a antiguidade e o exercício da educação hospitalar. Assim, como instrumento de coleta de dados, utilizou questionário, análise documental, expressão escrita do paciente-aluno e técnica não-verbal de desenhos. Todos os instrumentos retornaram, com exceção de documentos das classes hospitalares, concluindo a autora que as práticas das classes hospitalares em questão "acontecem como ação imediata, mas ainda não assumiram proposta com estrutura administrativa e projeto pedagógico sistematizado" (2002, p. 74).

Sob esse prisma, emerge a necessidade de realizar uma discussão aliando o desenvolvimento organizacional, ou o processo de gestão, ao caráter institucional das classes hospitalares, a fim de construir subsídios teóricos e práticos que possibilitem o aperfeiçoamento da estruturação dos ambientes hospitalares de ensino, libertando-se das atuações amadoras. Como referencia Nóvoa: "os processos de mudança e de inovação educacional passam pela compreensão 
ZARDO, S. P.; FREITAS, S. N. Educação em classes hospitalares: transformando ações e concepções à luz da teoria da complexidade

das instituições escolares em toda a sua complexidade técnica, científica e humana" (1995, p. 16).

Assim, o contexto atual convida a comunidade escolar a repensar o papel da educação na sociedade, seu processo organizacional e a possibilidade de o ato de educar transcender os espaços escolares, atendendo também crianças impossibilitadas de freqüentar o espaço da instituição escolar. Da mesma forma, faz-se mister recorrer a pressupostos teóricos que considerem a complexidade humana como base da ação pedagógica, já que estamos evidenciando que a não consideração da condição existencial do homem tem ocasionado a falta de aperfeiçoamento da convivência e a negação da prudência no âmbito científico e social.

Dessa forma, Santos (2002a, 2002c) revela que estamos em um período de transição paradigmática, um período no qual estão sucumbindo as bases sólidas que orientavam o pensamento e o conhecimento humano, um período no qual não há respostas definitivas para as questões que acompanham a existência humana.

Assim, o paradigma da modernidade entra em crise, por sua incapacidade de responder às problemáticas atuais e renovar sua produção epistemológica. A incapacidade de considerar a incerteza e a complexidade dos fenômenos humanos também contribuiu para o fracasso da ciência moderna, caracterizada por isolar dados, hierarquizá-los e separar o sujeito do objeto de conhecimento.

Santos (2002c) diz que o modelo de racionalidade que presidiu a ciência moderna se constituiu a partir da revolução científica do século XVI e foi desenvolvido nos séculos seguintes no domínio das ciências naturais, e somente no século XIX se estendeu às ciências sociais emergentes. Segundo o autor,

A partir de então pode falar-se de um modelo global de racionalidade científica que admite variedade interna, mas que se distingue e defende por via de fronteiras ostensivas e ostensivamente policiadas de duas formas de conhecimento não científico (e, portanto, irracional) potencialmente perturbadoras e intrusas: o senso comum e as chamadas humanidades ou estudos humanísticos (em que se incluíram, entre outros, os estudos históricos, jurídicos , literários, filosóficos e teológicos) (SANTOS, 2002c, p. 10). 
Esses princípios desenvolvidos na modernidade buscaram compreender o ser humano a partir da distinção corpo/mente, razão/emoção, buscando separar o sujeito do objeto de conhecimento, dificultando, inclusive, o processo do sujeito de conhecer a si mesmo. Tal fragmentação implantada pela ciência moderna ${ }^{1}$ impede a configuração de uma visão holística ${ }^{2}$ da existência humana e, embora se tenham alcançado alguns avanços no que tange à evolução científica e à industrialização, no que diz respeito ao entendimento da condição humana, no sentido de aperfeiçoar a convivência social, poucas contribuições podem ser evidenciadas.

Esses pressupostos científicos e epistemológicos, oriundos da Revolução Industrial, acabaram por influenciar a produção do conhecimento sobre o homem, comparando-o a uma máquina, que pode ser entendida a partir do singular funcionamento de suas partes, sem considerar a inter-relação existente entre estas na constituição de sua totalidade.

Constituiu-se, dessa forma, um paradigma de conhecimento científico que foi utilizado pela elite mundial para ditar as normas do que e para quem devem ser realizadas as investigações na ciência. Morin (2003) aponta que o problema da organização desse conhecimento vigente é que ele opera por seleção de dados significativos e rejeição de dados não significativos, pois separa (desune) e une (associa); hierarquiza (o principal) e centraliza (conforme núcleo de noções mestras). Diante disso, o autor aponta a necessidade de evitar essa visão unidimensional e ressalva que "é preciso previamente tomar consciência da natureza e das conseqüências dos paradigmas que mutilam o conhecimento e desfiguram o real" (Morin, 2003, p. 16).

Realizando uma breve análise do atendimento educacional para crianças hospitalizadas, verifica-se que essa prática começou a ser organizada e regulamentada com maior incidência principalmente a partir da década de 1990, na qual intensificam-se as propostas de democratização de ensino, acessibilidade e inclusão.

${ }^{1}$ Não cabe aqui, neste trabalho, julgar a ciência moderna, pois se sabe que muitas foram as suas contribuições. Apenas pretende-se discutir seus pressupostos fundantes e a interferência destes na consideração da condição humana, especificamente no tratamento de saúde ou internação hospitalar.

2 Utiliza-se do termo "holístico" com o mesmo sentido atribuído por Abbagnano (2000), que define o termo como "uma variante da doutrina da evolução emergente, que consiste na inversão da hipótese mecanicista e em considerar que os fenômenos biológicos não dependem dos fenômenos físico-químicos, mas ao contrário" (2000, p. 512). 
ZARDO, S. P.; FREITAS, S. N. Educação em classes hospitalares: transformando ações e concepções à luz da teoria da complexidade

Pode-se observar então, certo avanço daquelas concepções que postulavam a fragmentação humana na modernidade, para uma perspectiva que atualmente prevê em lei, além do direito de freqüentar instituições educacionais, o direito da criança com alguma limitação de participar de serviços que envolvem equipes multidisciplinares (médicos, psicólogos, fisioterapeutas, educadores especializados, etc.). Essas ações buscam desenvolver as potencialidades dos sujeitos com necessidades educacionais especiais em suas diferentes dimensões, considerando-as igualmente relevantes.

Considerando que a criança hospitalizada permanece em desenvolvimento cognitivo, afetivo e psicossocial, foram elaborados os Direitos da Criança e do Adolescente Hospitalizados, que, além de assegurar o direito da criança de ser hospitalizada, garantindo a proteção, a vida e a saúde, afirma o "Direito de desfrutar de alguma forma de recreação, programas de educação para a saúde e acompanhamento do currículo escolar durante sua permanência hospitalar" (Declaração dos Direitos da Criança e Adolescente Hospitalizados, Resolução $\mathrm{n}^{\text {o }} 41$ de 13 de outubro de 1995).

Sob esse prisma, a classe hospitalar pode ser considerada um ambiente educativo dentro do hospital que propicia a construção saudável da subjetividade, já que o evento da hospitalização é desconhecido por vários pacientes-alunos e repercute em afastamento do lar, da família, dos amigos e da escola.

Logo, a conexão entre o pedagógico e o ambiente hospitalar pode surtir atitudes positivas que auxiliam a criança em relação ao tratamento, à aprendizagem, às relações interpessoais, fornecendo encorajamento para enfrentar a hospitalização. Nesse sentido, Plank comenta que

\begin{abstract}
Cuando se interna un niño, el hospital tiene que asumir tareas que están más allá de la función curativa, tareas que deben cumplirse de manera tal que el ritmo de vida y de crecimiento pueda continuar. La forma normal de vida del niño implica su relación con otros niños, con los adultos, con el juego y el aprendizaje (1966, p. 13).
\end{abstract}

Dessa forma, supera-se o entendimento de considerar a criança apenas um paciente em tratamento na unidade hospitalar, mas passa-se a ponderar seus interesses, desejos e necessidades. Como comenta Ceccim: "a aprendizagem de crianças doentes dentro do hospital é possível, pois estão doentes, mas em tudo continuam crescendo" $(1997$, p. 80$)$.

Nesse sentido, a Resolução n ${ }^{\circ}$ 02/2001 - CEB/CNE, que estabelece as dire- 
trizes nacionais para a educação especial na educação básica, propõe em seu art. 13 , parágrafo $1^{\circ}$, que as classes hospitalares devem dar continuidade ao processo de desenvolvimento e aprendizagem de alunos matriculados em escolas da Educação Básica, contribuindo para o retorno e reintegração ao grupo escolar, desenvolvendo um currículo flexibilizado com crianças, jovens e adultos não matriculados no sistema educacional local, facilitando o posterior acesso à escola regular.

Assim, segundo a Política Nacional de Educação Especial, define-se classe hospitalar como: "Ambiente hospitalar que possibilita o atendimento educacional de crianças e jovens internados que necessitam de Educação Especial e que estejam em tratamento hospitalar"' (MeC/SEESP, 1994).

Como a enfermidade é um fator considerável de desajuste para a criança e sua família, é necessário que os profissionais, em caráter multidisciplinar, busquem compreender a situação que a criança está vivenciando. Surge, então, a necessidade de uma "escuta pedagógica", termo sugerido por Ceccim:

Quando propomos uma escuta pedagógica à criança hospitalizada, estamos propondo lançar um novo pensar à atenção de saúde da criança que está doente e vivencia a internação hospitalar. Sua vida não só continua em processo de aquisição de aprendizagens formais, como tem no seu desenvolvimento intelectual uma importante via de apropriação compreensiva do que lhe acontece no hospital e na estimulação cognitiva, uma instalação do desejo de vida, que pode repercutir com vontade de saúde para o restabelecimento ou para a produção de modos positivos de viver, uma vez que o aprender se relaciona com a construção de si e do mundo (1997, p. 76).

A discussão de pressupostos que possibilitem a melhoria da assistência em saúde para crianças em tratamento de saúde requer que seja considerada, primeiramente, a condição humana do sujeito internado na instituição hospitalar. Nessa perspectiva, a referência à condição humana significa considerar a complexidade da pessoa hospitalizada, transcendendo apenas o cuidado com a saúde fisiológica/biológica.

Nesse sentido, é necessário destacar que o evento da hospitalização interfere na dinâmica da existência do sujeito, fazendo com que encontre no contexto hospitalar um novo parâmetro de sua existência, redimensionando questões que envolvem a doença, a morte e a própria perspectiva existencial. Segundo Angerami: 
ZARDO, S. P.; FREITAS, S. N. Educação em classes hospitalares: transformando ações e concepções à luz da teoria da complexidade

O processo de hospitalização deve ser entendido não apenas como um mero processo de institucionalização hospitalar, mas, e principalmente, como um conjunto de fatos que decorrem desse processo e suas implicações na vida do paciente (1995, p. 24).

Considerar o evento da hospitalização como um fator interferente na existência do sujeito requer, além da atenção à condição humana, o questionamento desta, implicando a reflexão sobre a posição desse homem no mundo. Assim, a ciência moderna influi diretamente na maneira como concebemos a condição humana. E, segundo Morin (2002), isso constitui um problema epistemológico que resulta no fato de se tornar impossível conceber a unidade complexa humana pelo pensamento disjuntivo, pois este concebe a humanidade fora do cosmos que a rodeia, da matéria física e do espírito que constitui o ser humano, bem como pelo pensamento redutor, que restringe a unidade humana a um substrato puramente bio-anatômico.

Colocar em evidência a multidimensionalidade e a complexidade humana no tratamento de enfermidades demanda mudanças de concepções, superação do entendimento reducionista em relação ao paciente hospitalizado e a consideração de que, mesmo hospitalizada, a pessoa tem desejos, necessidades e vontades e, muitas vezes, o enrijecimento do hospital impede não somente a realização, mas a expressão desses sentimentos. Nas palavras de Angerami: "A humanização do hospital necessariamente passa por transformações da instituição hospitalar como um todo e evidentemente pela própria transformação social" (1995, p. 27).

Assim, a inserção de pressupostos humanizadores no hospital faz com que a instituição reveja seus próprios postulados no que tange aos conceitos adotados até então, fazendo desse processo de compreensão existencial do outro um pilar de escoramento no tratamento à saúde.

Como pontua Ortiz (2003), o paciente infantil, ao instalar-se na unidade de tratamento, já está infligido pelas incômodas sensações corporais e, além disso, terá de assumir o enfrentamento de outras situações, como as limitações de seu corpo, a separação da sua família, dos amigos e da escola, as dúvidas quanto ao seu futuro e em relação ao estar incluído nos padrões de normalidade e a adaptação ao desconhecido mundo branco hospitalar.

A medicina e o tratamento de saúde pautados em pressupostos reducionistas favorecem o processo de despersonalização do paciente, que deriva principalmente da fragmentação ocorrida com diagnósticos cada vez mais específicos, que abordam a pessoa a partir de um determinado sintoma e 
reduzem o espaço vital do ser humano a um mero determinismo das implicações de certos diagnósticos carregados de estigmas e preconceitos. Como referencia Serino:

El ser humano despojado de sus características esenciales se transforma en un objetivo, un número de cama, un síndrome o un órgano enfermo. Al enfermo sólo le queda (desde esta perspectiva) asistir al total aniquilamiento de sus derechos y adaptarse a la situación que le permitirá "recuperar" su salud (1990, p. 26).

Nesse sentido, deve-se atentar para o processo de despersonalização pelo qual passa o paciente ao ser hospitalizado e as conseqüências que tal evento pode ocasionar no desenvolvimento global do sujeito. O estigma de doente para a criança hospitalizada e a sua condição de passividade perante os acontecimentos interferem no processo de construção de valores intra e interpessoais e na elaboração de conceitos de homem e mundo. Com isso, o fato de ser "hospitalizada" faz com que a criança adquira signos que irão enquadrá-la num novo desempenho existencial, pois seu processo vital não depende mais da sua escolha, mas seus hábitos anteriores terão de ser reformulados e transformados diante da realidade da hospitalização e da doença (ANGERAmi, 1995). Na perspectiva de Ceccim:

A enfermidade e a hospitalização das crianças passam por seu corpo e emoções, passam por sua cultura e relações; produzem afetos e inscrevem conhecimentos sobre si, o outro, a saúde, a doença, o cuidado, a proteção, a vida. A corporeidade e a inteligência vivenciam essas informações como conhecimento e saber pessoal (1997, p. 33).

Considerando que o hospital e a enfermidade produzem para a criança uma relação diferenciada e peculiar com o mundo, é necessário redimensionar ações que busquem contemplar as diferentes dimensões constituintes do ser humano. Assim, os saberes inerentes à medicina não podem desprezar a relevância dos atos objetivos da construção singular da existência. Nas palavras de Ceccim: 
ZARDO, S. P.; FREITAS, S. N. Educação em classes hospitalares: transformando ações e concepções à luz da teoria da complexidade

Uma adequada possibilidade de acolhimento dos medos, desejos, ansiedades, confusões e ambivalências, com adequado nível de informação, permitirá, portanto, a produção de conhecimentos sobre si e uma construção positiva a respeito da saúde, em que o corpo não se separe do pensamento (a noção e permissão ao corpo-pensamento como unidade se diferencia da experiência de corpo vivido como oposição ao pensamento/emoções - o biológico versus o psicológico) (1997, p. 34).

Ao comentar acerca da necessidade de a educação do futuro ser centrada na condição humana, Morin (2002) afirma que os seres humanos, onde quer que se encontrem "[...] devem reconhecer-se em sua humanidade comum e ao mesmo tempo reconhecer a diversidade cultural inerente a tudo que é humano" (2002, p. 47).

Sob esse prisma, quando o autor discorre acerca dos pressupostos que possibilitam ao homem tornar-se humano, destaca quatro elementos: a unidualidade, ou seja, a possibilidade de o homem ser a um só tempo um ser plenamente biológico e plenamente cultural; o circuito cérebro/mente/cultura, no qual o homem somente se realiza plenamente como ser humano pela cultura e na cultura, portanto, a mente humana é uma criação que emerge e se afirma na relação cérebro-cultura; o circuito razão/afeto/pulsão, tríade inseparável e frágil, não hierarquizada, que integra a humanidade e a animalidade; o circuito indivíduo/sociedade/espécie, no qual os indivíduos são produtos do processo reprodutor da espécie humana, sendo esse processo realizado por interações entre indivíduos que produzem a sociedade, que testemunha o surgimento da cultura, logo, são a cultura e a sociedade que garantem a realização dos indivíduos que permitem a perpetuação da cultura e a auto-organização da sociedade (Morin, 2002).

A partir da proposição desses elementos, pode-se evidenciar que o autor procura trabalhar a complexidade humana a partir de diferentes constituintes, mas não sobrepondo uma às demais. $\mathrm{O}$ homem, nessa perspectiva, é considerado um ser único, mas simultaneamente parte do coletivo, no qual se fundem os princípios cérebro, mente, cultura, razão, afeto, pulsão, indivíduo, sociedade e espécie. Ou seja, a humanidade do homem, antes de ser desenvolvida individualmente, provém do campo da coletividade, em que unidade e diversidade 
são entrelaçadas. Nas palavras de Morin:

A complexidade humana não poderia ser compreendida dissociada dos elementos que a constituem: todo desenvolvimento verdadeiramente humano significa o desenvolvimento conjunto das autonomias individuais, das participações comunitárias e do sentimento de pertencer à espécie humana $(2002$, p. 55).

É no sentido de continuar a pertencer à sociedade que se reitera a necessidade da existência de classes hospitalares nas instituições responsáveis pelo tratamento de saúde. A classe hospitalar aparece como espaço responsável pela promoção de situações nas quais são valorizadas as inquietudes existenciais das crianças hospitalizadas, onde se busca, durante a internação, considerar a condição humana da criança. Ou ainda, a classe hospitalar possibilita que a criança continue a construção de conhecimentos - sistematizados ou não -, buscando a reintegração desse sujeito na escola e na sociedade após a finalização do tratamento. Assim, cabe a articulação entre educação e saúde, na tentativa de considerar a complexidade da criança hospitalizada e a necessidade de aprimorar os atendimentos a partir da análise de como se estruturam esses ambientes educacionais.

\section{REFERÊNCIAS}

ABBAGNANO, N. Dicionário de filosofia. São Paulo: Martins Fontes, 2000.

ANGERAMI-CAMON, V. A. O psicólogo no hospital. In: TRUCHARTE, F. A. R. et al. Psicologia hospitalar: teoria e prática. São Paulo: Pioneira, 1995. p. 15-28.

BRASIL. Política nacional de educação especial. Brasília: MEC/Seesp, 1994. . Declaração dos direitos da criança e adolescente hospitalizados. Resolução $\overline{\mathrm{n}^{\circ} 41}$ de 13 de outubro de 1995. Brasília: Imprensa Oficial, 1995. 
ZARDO, S. P.; FREITAS, S. N. Educação em classes hospitalares: transformando ações e concepções à luz da teoria da complexidade

. Diretrizes nacionais para a educação especial na educação básica. Secretaria de Educação Especial-MEC; Seesp, 2001

CECCIM, R. B.; CARVALHO, P. R. A. Criança hospitalizada: atenção integral como escuta a vida. Porto Alegre: UFRGS, 1997.

FONSECA, E. S. da. Atendimento escolar no ambiente hospitalar. São Paulo: Memnon, 2003.

. Estudos e pesquisas sobre atendimento em classe hospitalar. Disponível em: $<$ http://www.2uerj.br/ escolahospitalar>. Acesso em: 22/5/2005.

MORIN, E. Os sete saberes necessários à educação do futuro. São Paulo: Cortez, 2002.

. Introdução ao pensamento complexo. 4. ed. Lisboa: Instituto Piaget, 2003.

NÓVOA, A. Para uma análise das instituições escolares. In: NÓVOA, A. (Org.). As organizações escolares em análise. Rio de Janeiro: Dom Quixote, 1995.

ORTIZ, L. C. M.; FREITAS, S. N. Classe hospitalar: reflexões sobre a sua práxis educativa. Dissertação (Mestrado em Educação) - Universidade Federal de Santa Maria, Santa Maria, 2002.

. Classe hospitalar: espaço de possibilidades pedagógicas. Cadernos de Ensino, Pesquisa e Extensão, Santa Maria, n. 54, 2003.

PLANK, E. El cuidado psicológico del niño enfermo en el hospital. Buenos Aires: Paidós, 1966.

SANTOS, B. de S. A crítica da razão indolente: contra o desperdício da experiência. Para um novo senso comum: a ciência, o direito e a política na transição paradigmática. São Paulo: Cortez, 2002.

. Democratizar a democracia: os caminhos da democracia participativa. Rio de Janeiro: Civilização Brasileira, 2002.

. Um discurso sobre as ciências. Porto: Edições Afrontamento, 2002.

SERINO, F. Aspectos psicosociales de la hospitalizacion en los niños. Revista Niños, v. 25, n. 71, p. 27-49, jul./dic. 1990.

Texto recebido em 12 ago. 2006

Texto aprovado em 23 nov. 2006 